\title{
RESEARCH
}

Open Access

\section{Radiologic findings that aid in the reduction of misdiagnoses of Langerhans cell histiocytosis of the bone: a retrospective study}

Mimi Zhao, Limin Tang, Shiqing Sun, Jiufa Cui and Haisong Chen ${ }^{*}$ (1)

\begin{abstract}
Background: This study aimed to identify the characteristic radiological signs for the diagnosis of Langerhans cell histiocytosis $(\mathrm{LCH})$ of the bone.

Methods: We retrospectively studied 82 cases of LCH with bone lesions confirmed by pathology. Clinical and radiological features of the patients were analyzed.

Results: A total of 64 and 18 patients had single and multiple bone lesions, respectively. With regard to LCH with single bone lesions, 37.5\% (24/64) of lesions were located in the skull and presented as bone destruction with or without soft tissue mass. The correct diagnosis rate of these lesions was $60.0 \%(9 / 15)$ in children and adolescents, but was only $22.2 \%(2 / 9)$ in adults.

A total of $26.5 \%(17 / 64)$ of the solitary lesions were found in the spine. Of these, $88.2 \%(15 / 17)$ were located in the vertebral body and appeared to have different degrees of collapse, and $66.7 \%(10 / 15)$ of these lesions were correctly diagnosed.

Of the unifocal lesions, 21.8\% (14/64) were located in other flat and irregular bones and manifested as osteolysis. Only $21.4 \%(3 / 14)$ of these cases were correctly diagnosed.

In total, $14.1 \%(9 / 64)$ of the isolated bone LCH lesions were located in the long bones. Of these, $77.8 \%(7 / 9)$ were located in the diaphysis and presented as central bone destruction with or without fusiform periosteal reaction and extensive peripheral edema, of which $42.9 \%$ (3/7) were correctly diagnosed before surgery or biopsy.

With regard to LCH with multiple bony destructive lesions, $71.4 \%$ (10/14) of cases in children and adolescents were correctly diagnosed; however, all four cases among adults were misdiagnosed.

Conclusion: In all age groups, isolated diaphyseal destruction of the long bone with fusiform periosteal reaction and extensive peripheral edema, vertebra plana of the spine, and bevelled edge of skull defects accompanied by soft tissue masses strongly suggest LCH diagnosis. Moreover, the multiple bone osteolytic destruction in children and adolescents strongly suggests LCH diagnosis. Familiarity with these typical radiological signs of LCH is necessary to decrease misdiagnoses.
\end{abstract}

Keywords: Langerhans cell histiocytosis, Radiology, Differential, Diagnostic imaging, Bone lesion

\footnotetext{
*Correspondence: abluesky12345@163.com

Department of Radiology, The Affiliated Hospital of Qingdao University,

Qingdao 266003, China
}

C C The Author(s). 2021 Open Access This article is licensed under a Creative Commons Attribution 4.0 International License, which permits use, sharing, adaptation, distribution and reproduction in any medium or format, as long as you give appropriate credit to the original author(s) and the source, provide a link to the Creative Commons licence, and indicate if changes were made. The images or other third party material in this article are included in the article's Creative Commons licence, unless indicated otherwise in a credit line to the material. If material is not included in the article's Creative Commons licence and your intended use is not permitted by statutory regulation or exceeds the permitted use, you will need to obtain permission directly from the copyright holder. To view a copy of this licence, visit http://creativecommons.org/licenses/by/4.0/ The Creative Commons Public Domain Dedication waiver (http://creativecommons.org/publicdomain/zero/1.0/) applies to the data made available in this article, unless otherwise stated in a credit line to the data. 


\section{Background}

Histiocytoses are rare disorders characterized by the accumulation of macrophages, dendritic cells, and monocyte-derived cells in various tissues and organs. Langerhans cell histiocytosis ( $\mathrm{LCH}$ ) was assigned to the Langerhans-associated disease (L) group [1]. LCH, the most common histiocytic disorder, is characterized by the accumulation of $\mathrm{CD} 1 \mathrm{~A}+/ \mathrm{CD} 207+$ mononuclear phagocytes within granulomatous lesions that can affect nearly all organ systems. Based on genetic, molecular, and functional data, $\mathrm{LCH}$ is defined as an inflammatory myeloid neoplasia [2].

$\mathrm{LCH}$ is categorized as a single-system LCH (SS-LCH) with multifocal or unifocal involvement, or as multisystem LCH (MS-LCH) with multiple organ involvement with or without risk organ involvement. Organs at risk include the hematopoietic system (bone marrow), spleen, and liver [3]. LCH may affect any organs, but those more frequently affected are the bones (80\% of cases), skin (33\%), pituitary gland (25\%), liver, spleen, hematopoietic system, lungs ( $15 \%$ each), lymph nodes $(5-10 \%)$, or the central nervous system (CNS) $(2-4 \%$, excluding the pituitary) [4]. The diagnosis of LCH is based on histological and immunophenotypic examinations. The primary indicators are characteristic LCH cells and positivity for CD1a and/or Langerin (CD207) cells. Confirmation of cytoplasmic Birbeck granules by electron microscopy is no longer necessary [5]. Radiological measures, including computed tomography $(\mathrm{CT})$ and magnetic resonance imaging (MRI), are also recommended to evaluate $\mathrm{LCH}$ and assist in diagnosis [6].

Although the skeletal system may be involved in $80 \%$ of $\mathrm{LCH}$ cases, the diagnosis of bone $\mathrm{LCH}$ by medical imaging remains challenging. Our study retrospectively evaluated 82 cases of $\mathrm{LCH}$ patients with bone lesions to identify the characteristic radiological signs for the correct diagnosis of $\mathrm{LCH}$ of the bone.

\section{Methods}

\section{Patients}

Patients with LCH confirmed by pathology who had undergone diagnostic imaging in our hospital were included in this study. A systematic computerized search of the hospital database was performed to identify eligible patients under the diagnostic code of $\mathrm{LCH}$ who were admitted between January 2008 and June 2020. The inclusion criteria were as follows: (1) patients with pathologically confirmed LCH; (2) patients who underwent X-ray, CT, or MRI examination prior to the initiation of surgical treatment; and (3) patients with bone lesions observed on imaging and had available imaging data.

Informed consent was obtained from all of the patients or their guardians. This study was approved by the ethics committee of our hospital. A total of 82 patients were included, with 64 and 18 patients having single and multiple bone lesions, respectively. Of all cases, 49 patients were male and 33 were female (male to female ratio $=1.5$ : $1)$. The demographics of the participants are shown in Table 1.

\section{Image acquisition}

Thirty minutes before the CT or MR scan, $5 \%$ chloral hydrate $(1 \mathrm{~mL} / \mathrm{kg})$ was orally administered to sedate the children when necessary.

X-rays were performed using the Philips DR system (Netherlands) and the Digital Diagnost Version workstation.

CT scans were performed using a GE (US) 128-slice CT scanner (Discovery CT 750HD) and Siemens (Germany) 64-slice CT machine. The scanning parameters were as follows: slice thickness, $0.6 \mathrm{~mm}$; tube voltage, $120-340$ keV; tube current, 80-240 mAs; and pitch, 1. After scanning, multiplanar reconstruction was performed to obtain the sagittal and coronal images. CT images with window levels of $250-350 \mathrm{Hu}$ and window widths of 1000-1500 $\mathrm{Hu}$ were used to observe bone structures; CT images with window levels of 40-60 $\mathrm{Hu}$ and window widths of 300$500 \mathrm{Hu}$ were used to observe soft tissues.

MR was performed using a US GE Signa $1.5 \mathrm{~T}$ and GE HDx 3.0T superconducting magnetic resonance scanner. The scanning matrix was $256 \times 192$, the layer thickness was $4 \mathrm{~mm}$, and the scanning sequence and its parameters were set as follows: SE T1WI (TR 400-600 ms, TE 5-25 ms); FSE T2WI (TR 3000-4000 ms, TE 80-105 $\mathrm{ms}$ ), and short-time inversion recovery sequences (STIR) or T2WI pre-saturated fat suppression sequences (TR 3000-4000 ms, TE 80-105 ms). Post-contrast scans were performed with fat-suppressed T1-weighted imaging (TR 400-600 ms, TE 5-25 ms) after intravenous injection of $0.2 \mathrm{mg} / \mathrm{kg}$ gadolinium-diethylenetriamine pentaacetic acid (Gd-DTPA, Magnevist, Bayer-Schering Pharma AG).

\section{Image analysis}

Two experienced skeletal radiologists who were blinded to the results of other tests, including pathological

Table 1 The demographic of patients with Langerhans cell histiocytosis with bone lesions

\begin{tabular}{lll}
\hline & Single & Multiple \\
\hline Patients (No.) & 64 & 18 \\
Sex (M/F) & $38 / 26$ & $11 / 7$ \\
Median age at diagnosis (Y) & $13.5(1-64)$ & $4.5(1-66)$ \\
Age distribution (No. [\%]) & & \\
$\quad$ Child (range, 1-17) & $37(57.8)$ & $14(77.8)$ \\
$\quad$ Adult (range, 19-66) & $27(42.2)$ & $4(22.2)$ \\
\hline
\end{tabular}

No. number of patients 
diagnosis, evaluated the images separately. The location, number, and imaging characteristics of the lesions were recorded. If the two radiologists disagreed, a consensus was reached through discussion.

The patients were followed-up every month for the first 3 months, every 3 months for the first year, annually for the next 2 years, and biennially thereafter. Radiological examination at follow-up included radiography, CT, or MR examination.

\section{Statistical analyses}

The incidence of LCH lesions at different sites and the rate of preoperative misdiagnosis were compared. Continuous data were summarized as medians and ranges, and categorical data were calculated using frequency counts and percentages. The diagnostic consistency of the two radiologists was calculated using the kappa value. The strength of agreement was considered good for values between 0.76 and 1.00 .

\section{Results}

\section{Imaging modalities and diagnosis}

X-ray, CT, and MR images were available for 29 patients, and the correct diagnosis rate of these cases was $51.7 \%(15 / 29)$. X-ray and CT studies were performed for another 53 patients and the correct diagnosis rate of these cases was $41.5 \%(22 / 53)$. The correct diagnosis rate did not differ between groups $(P>0.05)$.

\section{Lesion distribution and symptoms}

The two evaluators agreed on the outcomes of all patient image evaluations and exhibited good consistency $(K=0.90)$.

The distribution and number of skeletal lesions among the patients are shown in Table 2-a total of 172 lesions. A total of 64 patients had single bone lesions. On the other hand, 18 patients had multiple lesions, with 108 total lesions among these 18 cases.

The clinical symptoms of LCH patients are shown in Table 3.

\section{Radiographic findings and diagnosis}

Regarding LCH with single bone lesions, 37.5\% (24/64) of lesions were located in the skull/cranial-facial bone. These lesions presented as bone destruction (100\%, 24/ $24)$, bevelled edge $(50.0 \%, 12 / 24)$, soft tissue mass $(79.2 \%, 19 / 24)$, and the correct diagnosis rate of these lesions was $60.0 \%(9 / 15)$ among children and adolescents, but only $22.2 \%$ (2/9) in adults.

Seventeen patients $(26.5 \%, 17 / 64)$ had isolated spine bone LCH lesions. Of these, $88.2 \%$ (15/17) were located in the vertebral body and appeared as different degrees of collapse $(100 \%, 15 / 15)$, vertebral plana $(33.3 \%, 5 / 15)$, obvious surrounding marrow and soft tissue edema $(60 \%, 9 / 15)$, and soft-tissue extension $(53.3 \%, 8 / 15)$, with $66.7 \%(10 / 15)$ being correctly diagnosed. Of these, $11.8 \%$ $(2 / 17)$ only involved the vertebral arch and/or posterior elements, which were misdiagnosed as metastatic tumors or infectious diseases, respectively.

Nine patients $(14.1 \%, 9 / 64)$ had isolated long-bone LCH lesions. Of these, 77.8\% (7/9) affected the diaphysis and presented as the central bone destruction. Other manifestations included fusiform periosteal reaction $(71.4 \%, 5 / 7)$ and extensive surrounding marrow and soft tissue edema $(57.1 \%, 4 / 7)$, with $42.9 \%$ (3/7) being correctly diagnosed before the surgical procedure or biopsy. Of these, $22.2 \%(2 / 9)$ were located in the metaphysis or epiphysis and presented as the bone destruction involving the epiphyseal plate. All of these were misdiagnosed as osteoblastomas and infectious diseases, respectively.

In total, $21.8 \%(14 / 64)$ of the isolated lesions of $\mathrm{LCH}$ were located in other flat and irregular bones (including the mandible, pelvis, rib bone, etc.). These lesions manifested as osteolysis $(100 \%, 14 / 14)$, soft tissue mass $(35.7 \%, 5 / 14)$, soft tissue edema $(14.3 \%, 2 / 14)$, and pathological bone $(21.4 \%, 3 / 14)$, with only $21.4 \%$ (3/14) being correctly diagnosed.

Multiple sites were involved among the $18 \mathrm{LCH}$ patients presenting with multiple bony destruction. Of the cases among children and adolescents, 71.4\% (10/14) were correctly diagnosed; however, the four adults were all misdiagnosed (0/4). Three of them were misdiagnosed with

Table 2 Localization and number of skeletal lesions among patients with Langerhans cell histiocytosis

\begin{tabular}{|c|c|c|c|c|c|c|c|}
\hline \multirow[t]{2}{*}{ Localization } & \multicolumn{3}{|c|}{ Single lesion } & \multicolumn{3}{|c|}{ Multiple lesions } & \multirow{2}{*}{$\begin{array}{l}\text { Total } \\
(\%)\end{array}$} \\
\hline & Child & Adult & $\overline{\text { Total }(\%)}$ & Child & Adult & Total (\%) & \\
\hline Skull & 15 & 9 & $24(37.5)$ & 30 & 0 & $30(27.8)$ & $54(31.4)$ \\
\hline Spine & 7 & 10 & $17(26.6)$ & 23 & 10 & $33(30.6)$ & $50(29.1)$ \\
\hline Long bones & 9 & 0 & $9(14.1)$ & 13 & 0 & $13(12.0)$ & $22(12.8)$ \\
\hline Rib & 4 & 8 & $12(18.7)$ & 5 & 5 & $10(9.3)$ & $22(12.8)$ \\
\hline Pelvic bone & 1 & 0 & $1(1.6)$ & 13 & 2 & 15 (13.9) & $16(9.3)$ \\
\hline Others & 1 & 0 & $1(1.6)$ & 5 & 2 & $7(6.5)$ & $8(4.7)$ \\
\hline Total & 37 & 27 & $64(100)$ & 89 & 19 & $108(100)$ & $172(100$ \\
\hline
\end{tabular}

Others: includes the clavicle, scapula, and sternum 
Table 3 The clinical symptoms of patients with Langerhans cell histiocytosis with skeletal lesions

\begin{tabular}{llllll}
\hline & \multicolumn{2}{l}{ Single lesion } & & & Others \\
\cline { 2 - 5 } & Skull & Long bones & Spine & 13 & 9 \\
\hline Pain & 14 & 7 & 16 & 0 & 4 \\
Soft tissue mass & 7 & 0 & 0 & 0 & 0 \\
Ear drainage & 2 & 0 & 0 & 0 & 0 \\
Polydipsia/polyuria & 1 & 0 & 1 & 0 & 2 \\
Soft tissue welling & 1 & 1 & 0 & 0 & 1 \\
Restricted movement & 0 & 1 & 0 & 0 & 2 \\
Fever & 0 & 0 & 0 & 1 & 0 \\
No symptoms & 0 & 0 & & 0
\end{tabular}

Others: includes the pelvis, ribs, clavicle, scapula, and sternum

metastatic tumours, and one case was misdiagnosed as an infectious disease.

Among the LCH cases included in this study, 55 were treated in our hospital and had radiographic follow-up data. The treatment strategies were varied: 31 patients underwent surgery alone, 10 patients underwent surgery followed by chemotherapy, 13 patients received chemotherapy as the only treatment modality, and one patient did not receive any treatment. The mean follow-up duration for the 55 patients who received treatment averaged 27.6 months (range, 6-100 months). During the follow-up period, the primary lesions of 53 patients decreased or disappeared, and no new lesions appeared. Two or 3 months after treatment, sclerotic edges were observed in the lesions of four patients who received chemotherapy. Local recurrence of $\mathrm{LCH}$ was observed in only two children $(3.6 \%, 2 / 55)$. In one patient, the primary lesion was located in the temporal bone. However, a new lesion of the iliac bone was found 3 months after surgery during follow-up CT. Another patient was diagnosed with MS-LCH with multifocal and involved risk organs (bone marrow and liver). Three months after chemotherapy, this patient's CT showed an increase in the number of lesions.

\section{Discussion}

LCH may occur at any age, but it is mainly observed among children and adolescents [7, 8]. In our series of studies, children accounted for $62.2 \%(51 / 82)$ of the patients. Additionally, several studies have reported a male preponderance, citing ratios between 1.2 and 2.0 to 1 [9-11]. In our study population, the male to female ratio was $1.5: 1$, which is roughly similar to previously reported ratios. The findings of Reisi., et al. [12] revealed that the unifocal form was the most common form of bone involvement, which is similar to our findings. The clinical manifestations of $\mathrm{LCH}$ are diverse, and the most common clinical manifestation of patients with bone involvement is soft tissue mass accompanied by swelling or pain [4], which is consistent with our group. $\mathrm{LCH}$ can affect any bone, but it is more likely to occur in the skull, affecting $45-50 \%$ of patients $[9,13]$. In our series, the skull $(31.4 \%, 54 / 172)$ was most commonly affected, with the lesions mostly located in the calvaria $(59.3 \%$, $32 / 54$ ), followed by the maxillofacial and skull base bones, which is roughly similar to the findings in a previous study [9]. In the present study, $44.0 \%$ of the spine lesions $(22 / 50)$ were located in the thoracic vertebrae, followed by the lumbar and cervical vertebrae, which is consistent with the findings of Bertram et al. [14]. We also found that the long bone LCH lesions were mainly located in the femur $(10 / 22,45.5 \%)$, which is consistent with previous reports $[15,16]$. Long bone LCH reportedly affects mainly the metaphysis or diaphysis, but does not affect the epiphysis $[17,18]$; in the present study, two patients were observed to have $\mathrm{LCH}$ involvement in the epiphysis. Reisi., et al. [12] reported that the sternum, clavicle, scapula, and humerus were rare lesion locations. Similarly, they were rare in our study, with only 1 to 2 cases observed in each.

The typical imaging findings of LCH single cranial lesions are mainly round or oval bone defects, which are usually lytic, with clear boundaries (Fig. 1). Due to the asymmetrical destruction of the inner and outer plates, the LCH skull lesions appear to be "punched out." The destruction of the inner plate is usually greater than that of the outer plate, and bevelled edges can be observed [9]. As reported in a previous article, cases with characteristic bevelled edges are not common. However, 50\% (12/24) of the patients in our single cranial group exhibited this feature, all occurring in the calvarium, which may be due to the high proportion of calvarial lesions. Bone destruction may also be related to soft tissue masses [17]. A total of $79.2 \%$ of the lesions (19/24) in our group were accompanied by soft tissue masses. However, the "bevelled edges" are not unique to LCH. Myelomas and bone epidermoid cysts can also exhibit this feature [19]. However, myeloma is often accompanied by osteoporosis. Lytic lesions of the 


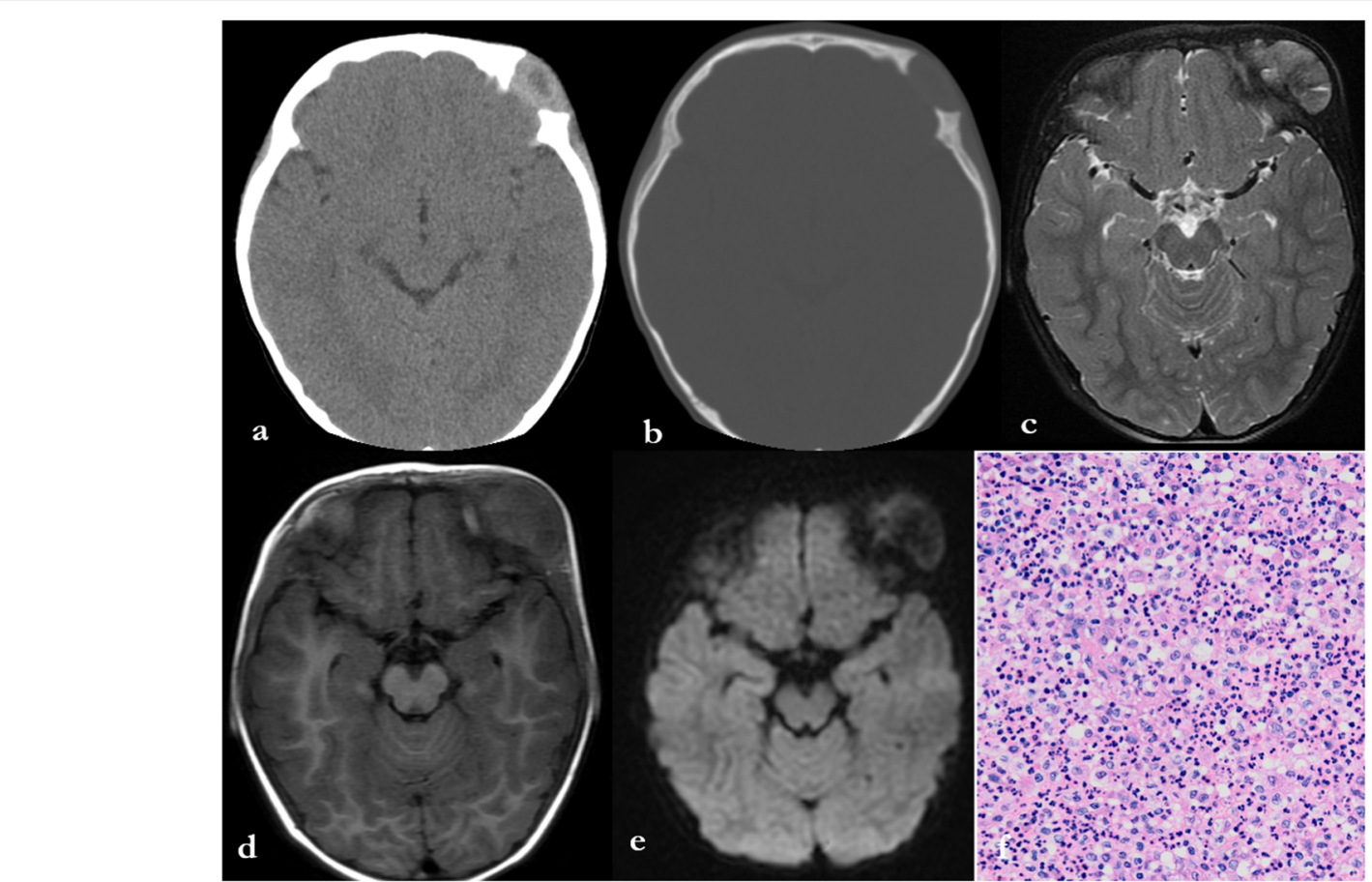

Fig. 1 Axial computed tomography of a 2-year-old male patient $(\mathbf{a}, \mathbf{b})$ showing bevelled-edge appearance in the left frontal bone. Axial MR images show hyperintensity on T2WI (c), hypointensity on T1WI (d), and slight hypointensity on diffusion weighted imaging (e). The diagnosis of LCH was confirmed by pathology after surgery (pathological slice HE $\times 200)(\mathbf{f})$

skull are also typical presentations of osseous epidermoid cysts, but the inner table is generally more affected than the outer table [20]. Skull destruction of metastatic tumors may also be accompanied by soft tissue masses, which are difficult to distinguish, especially in adults [13]. In our study, the rate of correct diagnosis in children is much higher than that in adults, possibly because radiologists rarely consider metastatic tumors and myeloma in the differential diagnosis of pediatric patients.

The imaging features of typical spinal LCH lesions reported in the literature mainly include complete or incomplete collapse of the vertebral body, retention of the intervertebral disc space, and associated paravertebral soft tissue masses (Fig. 2). The vertebral plana is often

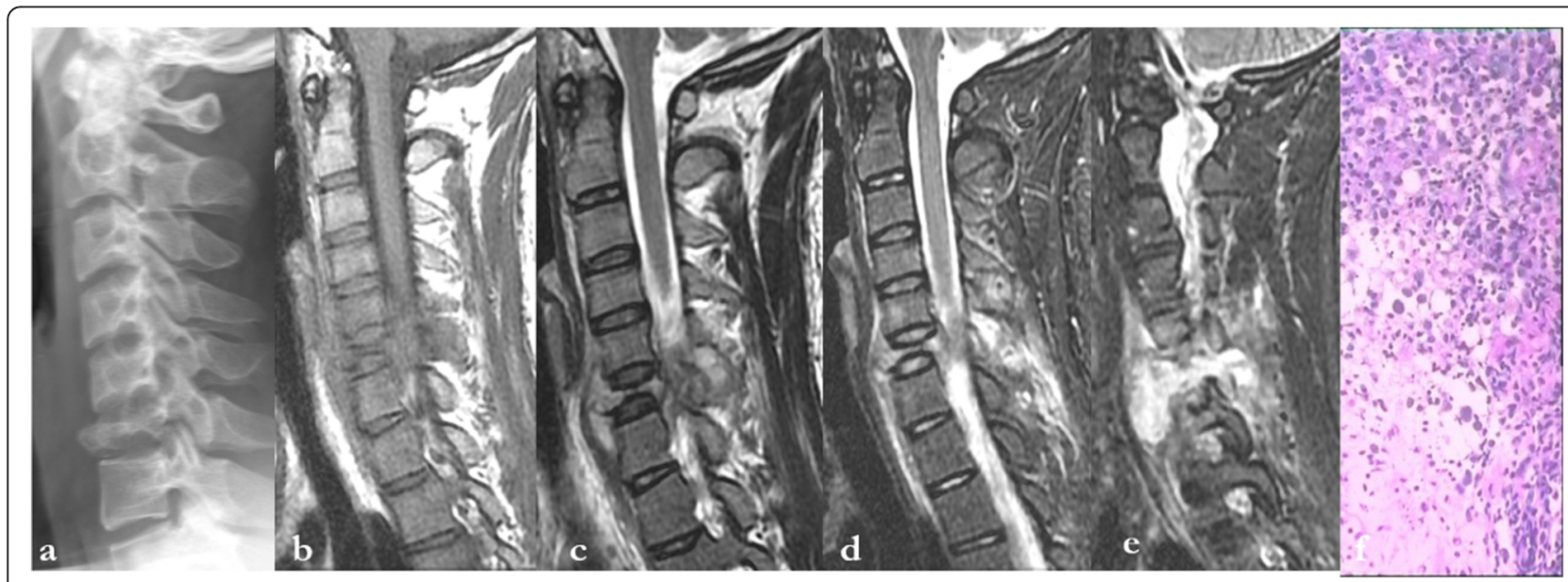

Fig. 2 Spinal X-ray and sagittal MR image of the cervical spine of a 19-year-old male patient with neck pain and restricted neck motion. X-ray (a) shows a lesion in the C6 associated with severe vertebral collapse. The lesion shows slight hypointensity on T1WI (b), hyperintensity on T2WI (c), and hyperintensity on fat-saturated T2WI (d, e), associated with obvious marrow and soft tissue edema, and prevertebral and epidural soft tissue extension. The diagnosis of LCH was confirmed by pathology after surgery (pathological slice HE $\times 200$ ) (f) 
observed in paediatric patients, and the diseased vertebral body may completely flatten into a coin shape [21]. In our study, typical vertebra plana accounted for only $33.3 \%$ (5/ 15) of cases in the vertebral body group, all of which were children. As described in the literature, the performance of the flat vertebrae is relatively specific but rare [22]. All patients with vertebral plana in our study were diagnosed correctly. With the popularity of CT and MRI, soft tissue extension has been reported in 50\% of cases [23]. In our series of studies, soft tissue extension was observed in $53.3 \%$ of lesions (8/15). Edema of the soft tissues around the vertebral body has rarely been reported in the literature, but we found it to be relatively common. In our group, 60\% (9/15) of the lesions had obvious edema in the surrounding soft tissues. Moreover, spine LCH lesions can extend to paravertebral soft tissues, and even involve the intervertebral disc space or endplate, which may be confused with malignant tumors such as metastatic tumors and myeloma, especially in older patients.

The typical imaging findings of LCH flat and irregular bone lesions reported in the literature are mainly dilated or lytic bone destruction. Rib lesions are often accompanied by pathological fractures, and soft tissue extension may cause extrapleural masses [24, 25]. In our series, only $21.4 \%(3 / 14)$ of the cases were associated with pathological fractures, and 35.7\% (5/14) were associated with soft tissue masses. No specific diagnostic signs were identified, and the diagnostic accuracy was very low.

The typical imaging findings of LCH long bone lesions reported in the literature are mainly round or oval clear radiolucent areas, which are mostly cystic or expansive bone destruction (Fig. 3) [26]. Periosteal reactions are common and vary in size, with characteristic multi-layer onion skin or single-layer morphology [27]. In our study, most of the lesions exhibited fusiform multilayer periosteal reactions. Moreover, long bone $\mathrm{LCH}$ is usually accompanied by extensive periosteal reaction, which needs to be distinguished from long bone malignancies such as Ewing's sarcoma. One of the differential points is that most LCH lesions are surrounded by obvious marrow and soft tissue edema due to the inflammatory medium released by $\mathrm{LCH}$; conversely, the peritumoral edema of the malignancy is relatively small due to the immune escape of the malignant tumors [28]. On the other hand, LCH that occurs at the metaphysis is difficult to distinguish from other diseases such as osteoblastoma and tuberculosis of the bone. In our study, both patients with lesions in the metaphysis were misdiagnosed.

In our cohort, the patients with multiple bone involvement sites presented with multiple bone destruction. $\mathrm{LCH}$ with multiple bone destruction lesions had a higher diagnostic accuracy rate in children $(71.4 \%, 10 / 14)$, but had been difficult to be correctly diagnosed in adults. With regard to $\mathrm{LCH}$ with multiple bone destruction lesions, no adult patient in our group was correctly diagnosed $(0 / 4)$. Three of them were older than 45 years and were misdiagnosed with metastatic tumors; among them, one patient had a history of prostate cancer. Another case of a young male was misdiagnosed as having an infectious disease due to the involvement of several adjacent vertebral bodies, which was very similar to infectious lesions. Because diseases associated with multiple

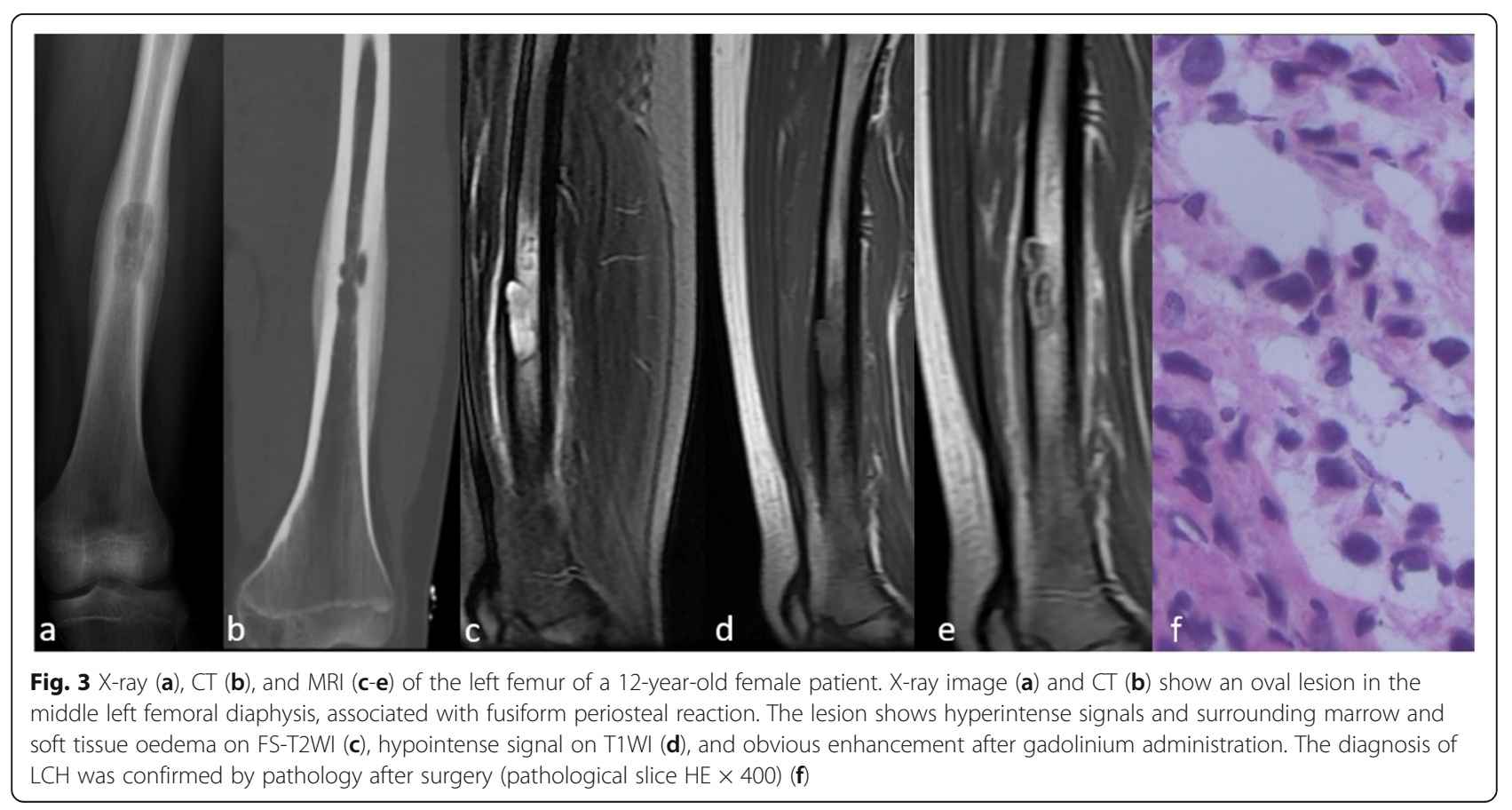


bone lesions other than $\mathrm{LCH}$ are rare in children, radiologists should prioritise $\mathrm{LCH}$ in the differential diagnosis of pediatric patients.

The prognosis of $\mathrm{LCH}$ also varies depending on the form of the disease (SS-LCH vs. MS-LCH), as well as its location and response to chemotherapy. In unifocal $\mathrm{LCH}$ involving a bone or isolated skin lesion, the prognosis is good. Spontaneous remission or symptoms that subsided after local treatment have been reported [3]. In forms with multifocal bone involvement, disease relapse occurs more often [5]. By contrast, the recurrence rate was low among our patients (3.6\%). This may be related to the patients we selected; in the present study, most cases had a single bone involvement. On the other hand, the emergence of marginal sclerosis has been reported as an indicator of mature and localised lesions [16]. However, it is rarely observed. This is consistent with our findings. At first, we observed sclerosis on the edge of the lesions in the follow-up CT images of four patients, with the lesions eventually becoming reduced or subsided and with no new lesions observed.

In general, among LCH patients with bone lesions, children are more likely to be diagnosed correctly than adults. In the present study, more than half of the children $(56.9 \%, 29 / 51)$ were correctly diagnosed by a radiologist. Solitary skull and spine lesions (for patients with single bone lesions) and multiple bone lesions in young patients have a high probability of being correctly diagnosed as LCH. The typical locations and imaging signs of $\mathrm{LCH}$ bone lesions increases the correct diagnostic rate of the disease by a radiologist.

Nevertheless, this study has some limitations. The retrospective design of the study means that there may be some confusion and bias. Non-uniform imaging techniques are also a limitation of our research, as not all patients had available X-ray, CT, and MR images of the bones. However, in our cohort, the diagnostic accuracy did not differ between groups of patients with different imaging modalities $(P>0.05)$. This indicates that the imaging modality of patients in this study did not influence diagnostic accuracy. One possible explanation for this is that most of the typical radiological signs of LCH (except for surrounding marrow edema) can be observed simultaneously on CT and MR. Finally, the study is also limited by its small sample size. Therefore, a multicenter study is required to evaluate more cases.

\section{Conclusions}

In most cases, the imaging findings of $\mathrm{LCH}$ with bone lesions are non-specific and can vary according to the location of the lesion and the disease progression. However, in all age groups, isolated diaphyseal destruction of the long bone with fusiform periosteal reaction and peripheral oedema, vertebra plana of the spine, and bevelled edge of the skull defects accompanied by soft tissue masses strongly suggest the diagnosis of $\mathrm{LCH}$. Moreover, the multiple bone osteolytic destruction in children and adolescents strongly suggests the diagnosis of $\mathrm{LCH}$. Familiarity with these typical radiological signs of $\mathrm{LCH}$ can decrease misdiagnoses.

\section{Abbreviations}

CT: Computed tomography; LCH: Langerhans cell histiocytosis; SSLCH: Single-system LCH; MS-LCH: Multisystem LCH; MR: Magnetic resonance; STIR: Short-time inversion recovery sequences

\section{Acknowledgements}

Not applicable.

\section{Authors' contributions}

$\mathrm{CH}$ designed the study and edited the manuscript. ZM and TL collected the data and wrote the manuscript. SS and CJ collected and analyzed the data.

The authors read and approved the final manuscript.

\section{Funding}

This study was funded by the Clinical Medicine $+X$ Project of The Affiliated Hospital of Qingdao University (Grant No. QDFY+X2021016).

Availability of data and materials

All data generated or analyzed during the study were included in this article.

\section{Declarations}

Ethics approval and consent to participate

The Ethics Committee of The Affiliated Hospital of Qingdao University approved the study. Informed consent was obtained from all these patients or their guardians.

\section{Consent for publication}

The written consent is available for review by the chief editor.

\section{Competing interests}

The authors declare that they have no competing interests.

Received: 8 March 2021 Accepted: 5 May 2021

Published online: 10 May 2021

References

1. Emile J, Abla O, Fraitag S, Horne A, Haroche J, Donadieu J, et al. Revised classification of histiocytoses and neoplasms of the macrophage-dendritic cell lineages. Blood. 2016;127(22):2672-81. https://doi.org/10.1182/blood-201 6-01-690636.

2. Berres $M$, Merad $M$, Allen CE. Progress in understanding the pathogenesis of Langerhans cell histiocytosis: back to histiocytosis X? Brit J Haematol. 2015; 169(1):3-13. https://doi.org/10.1111/bjh.13247.

3. Kobayashi M, Tojo A. Langerhans cell histiocytosis in adults: advances in pathophysiology and treatment. Cancer Sci. 2018;109(12):3707-13. https:// doi.org/10.1111/cas.13817.

4. Krooks J, Minkov M, Weatherall AG. Langerhans cell histiocytosis in children. J Am Acad Dermatol. 2018;78(6):1035-44. https://doi.org/10.1016/j.jaad.2017. 05.059.

5. Jezierska M, Stefanowicz J, Romanowicz G, Kosiak W, Lange M. Langerhans cell histiocytosis in children - a disease with many faces. Recent advances in pathogenesis, diagnostic examinations and treatment. Adv Dermatol Allergol. 2018;35(1):6-17. https://doi.org/10.5114/pdia.2017.67095.

6. Haupt R, Minkov M, Astigarraga I, Schäfer E, Nanduri V, Jubran R, et al. Langerhans cell histiocytosis (LCH): Guidelines for diagnosis, clinical workup, and treatment for patients till the age of 18 years. Pediatr Blood Cancer. 2013;60(2):175-84. https://doi.org/10.1002/pbc.24367.

7. Guyot-Goubin A, Donadieu J, Barkaoui M, Bellec S, Thomas C, Clavel J. Descriptive epidemiology of childhood Langerhans cell histiocytosis in France, 2000-2004. Pediatr Blood Cancer. 2008:51(1):71-5. https://doi.org/1 $0.1002 / \mathrm{pbc} .21498$ 
8. DiCaprio MR, Roberts TT. Diagnosis and management of Langerhans cel histiocytosis. J Am Acad Orthop Surg. 2014;22(10):643-52. https://doi.org/10 5435/JAAOS-22-10-643.

9. D'Ambrosio N, Soohoo S, Warshall C, Johnson A, Karimi S. Craniofacial and intracranial manifestations of langerhans cell histiocytosis: report of findings in 100 patients. Am J Roentgenol. 2008;191(2):589.

10. Yagci B, Varan A, Caglar M, et al. Langerhans cell histiocytosis: retrospective analysis of 217 cases in a single center. Pediatr Hematol Oncol. 2008;25(5): 399-408. https://doi.org/10.1080/08880010802107356.

11. Salotti JA, Nanduri V, Pearce MS, Parker L, Lynn R, Windebank KP. Incidence and clinical features of Langerhans cell histiocytosis in the UK and Ireland. Arch Dis Child. 2009;94(5):376-80. https://doi.org/10.1136/adc.2008.144527.

12. Reisi N, Raeissi P, Harati Khalilabad T, Moafi A. Unusual sites of bone involvement in Langerhans cell histiocytosis: a systematic review of the literature. Orphanet J Rare Dis. 2021;16(1):1. https://doi.org/10.1186/s13023020-01625-z.

13. Khung S, Budzik J, Amzallag-Bellenger E, et al. Skeletal involvement in Langerhans cell histiocytosis. Insights Into Imaging. 2013;4(5):569-79. https://doi.org/10.1007/s13244-013-0271-7.

14. Bertram C, Madert J, Eggers C. Eosinophilic granuloma of the cervical spine. Spine. 2002;27(13):1408-13. https://doi.org/10.1097/00007632-20020701000007.

15. Hashmi MA, Haque N, Chatterjee A, Guha S. Langerhans cell histiocytosis of long bones: MR imaging and complete follow up study. J Cancer Res Ther. 2012;8(2):286-8. https://doi.org/10.4103/0973-1482.98991.

16. Zhang X, Zhou J, Chai X, et al. The application of X-ray, computed tomography, and magnetic resonance imaging on 22 pediatric Langerhans cell histiocytosis patients with long bone involvement. Medicine. 2018; 97(17):e411.

17. Buchmann L, Emami A, Wei JL. Primary head and neck Langerhans cell histiocytosis in children. Otolaryngol Head Neck Surg. 2016;135(2):312-7.

18. Postini AM, Andreacchio A, Boffano M, Pagano M, Brach Del Prever A, Fagioli F. Langerhans cell histiocytosis of bone in children. J Pediatr Orthop B. 2012;21 (5):457-62. https://doi.org/10.1097/BPB.0b013e32835367c0.

19. Inci MF, Inci R, Ozkan F. Multidetector $C T$ findings of calvarial eosinophilic granuloma. Case Rep. 2013;2013(may22 1):r2013009698.

20. Ugga L, Cuocolo R, Cocozza S, Ponsiglione A, Stanzione A, Chianca V, et al. Spectrum of lytic lesions of the skull: a pictorial essay. Insights Into Imaging. 2018;9(5):845-56. https://doi.org/10.1007/s13244-018-0653-y.

21. Liang J, Zhong JL, Xiao GL, Zhong WQ, Hui SY. Langerhans cell histiocytosis of the cervical spine a single chinese institution experience with thirty cases. Spine. 2010;35(1):E8-15.

22. Huang WD, Yang XH, Wu ZP, Huang Q, Xiao JR, Yang MS, et al. Langerhans cell histiocytosis of spine: a comparative study of clinical, imaging features, and diagnosis in children, adolescents, and adults. Spine J. 2013;13(9):110817. https://doi.org/10.1016/j.spinee.2013.03.013.

23. Peng X, Pan T, Chen L, Huang G, Wang J. Langerhans' cell histiocytosis of the spine in children with soft tissue extension and chemotherapy. Int Orthop. 2009;33(3):731-6. https://doi.org/10.1007/s00264-008-0529-8.

24. Thomas M, Shen KR. Primary Tumors of the osseous chest wall and their management. Thorac Surg Clin. 2017;27(2):181-93. https://doi.org/10.1016/j. thorsurg.2017.01.012.

25. Udaka T, Susa M, Kikuta K, Nishimoto K, Horiuchi K, Sasaki A, et al. Langerhans cell histiocytosis of the clavicle in an adult: a case report and review of the literature. Case Rep Oncol. 2015;8(3):426-31. https://doi.org/1 $0.1159 / 000441415$

26. Stull M, et al. Langerhans cell histiocytosis of bone. Radiographics. 1992;12: $801-23$

27. Routy B, Hoang J, Gruber J. Pulmonary Langerhans cell histiocytosis with lytic bone involvement in an adult smoker: regression following smoking cessation. Case Rep Hematol. 2015;2015:1-5. https://doi.org/10.1155/2015/2 01536.

28. Woertler K. Benign bone tumors and tumor-like lesions: value of crosssectional imaging. Eur Radiol. 2003;13(8):1820-35. https://doi.org/10.1007/ s00330-003-1902-z

\section{Publisher's Note}

Springer Nature remains neutral with regard to jurisdictional claims in published maps and institutional affiliations.

\section{Ready to submit your research? Choose BMC and benefit from:}

- fast, convenient online submission

- thorough peer review by experienced researchers in your field

- rapid publication on acceptance

- support for research data, including large and complex data types

- gold Open Access which fosters wider collaboration and increased citations

- maximum visibility for your research: over $100 \mathrm{M}$ website views per year

At BMC, research is always in progress.

Learn more biomedcentral.com/submissions 